\title{
Serological and fluorescence studies of the heat stability of bovine lactoferrin
}

\author{
By AUGUSTIN BAER, MARKO OROZ AND BERNARD BLANC \\ Federal Dairy Research Institute, CH-3097 Liebefeld (Bern), Switzerland
}

(Received 30 May 1978)

\begin{abstract}
Summary. The heat denaturation of Fe-saturated lactoferrin (If) and Fe-free lactoferrin (apo-lf) was studied using the methods of micro-complement fixation and fluorescence. It was established that the change in conformation of apo-lf, induced by iron binding, conferred a higher heat stability to the molecule: the changes were observed at temperatures above $40^{\circ} \mathrm{C}$ for apo-lf and above $60^{\circ} \mathrm{C}$ for lf. The $\mathrm{Fe}-$ binding ability of the protein was partially independent of the degree of denaturation. Fluorescence analyses indicated that tryptophan residues were probably not directly involved in the metal binding. There was no evidence of antibodies interfering with the binding sites.
\end{abstract}

\section{INTRODUCTION}

Lactoferrin (If) is an Fe-binding glycoprotein originally isolated from human milk by Montreuil \& Mullet (1960) and independently by one of us (Blanc \& Isliker, 1961). It was prepared from bovine milk by Groves (1960) and has since been identified in various physiological fluids (Masson, Heremans \& Dive, 1966). It is similar to other Fe-binding proteins such as transferrin and conalbumin. Each of them has $2 \mathrm{Fe}-$ binding sites/molecule and consists of a single polypeptide chain. In contrast to human lf, only a limited number of studies has been devoted to the physico-chemical properties of the bovine protein. Bacteriostatic behaviour has been investigated by Bishop et al. (1976) and Law \& Reiter (1977). Spectroscopic analyses and iron-binding properties have been described (Brown \& Parry, 1974; Parry \& Brown, 1974). The thermal denaturation of If has been succinctly investigated by Rüegg, Moor \& Blanc (1977). We were thus interested in studying in more detail the heat-induced conformational changes of that protein. Since nutritionists have considered the addition of $\mathrm{Fe}$ to milk as a possible deterrent against the Fe-deficiency anaemia, it was estimated useful to examine the influence of heat-treatment on the Fe-binding capacity of the molecule.

\section{Reagents}

MATERIALS AND METHODS

Lactoferrin. Bovine lactoferrin saturated with $\mathrm{Fe}$ was prepared from first-d postpartum colostrum as previously described (Baer, Oroz \& Blanc, 1976a). Apo-lf was obtained by dissolving If in $0.15 \mathrm{M}-\mathrm{NaCl}$, then titrating the solution to $\mathrm{pH} 1.8$ with $0 \cdot 1 \mathrm{~N}-\mathrm{HCl}$, which rendered the solution colourless. The free $\mathrm{Fe}$ was removed by gel filtration on Sephadex G-25. The protein eluted with distilled water was stored 
in the lyophilized form. When Fe was added to the solubilized apo-lf, the fluorescence and serological properties were completely identical to those of the native lf.

Chemicals. Sephadex G-25, CM-Sephadex C-50 and DEAE-Sephadex A-50 were purchased from Pharmacia (Uppsala, Sweden). Nitrilotriacetic acid (NTA) and $N$-2-hydroxyethyl-piperazine- $N^{\prime}$-2-ethansulfonic acid (HEPES) were obtained from Fluka AG, Buchs, Switzerland. ${ }^{59} \mathrm{FeCl}_{3}$ was purchased from The Radiochemical Centre, Amersham, Bucks., England. Other reagents were of analytical grade.

Solutions. Lf and apo-lf were dissolved in 0.1 M-HEPES buffer containing $0.01 \mathrm{M}$ $\mathrm{NaHCO}_{3}$ adjusted to $\mathrm{pH} 7 \cdot 0$ with $0.1 \mathrm{M}-\mathrm{KOH}$. The chelate complex Fe (III)-NTA was prepared as described by Bates \& Wernicke (1971). Since the solution is not very stable, it was prepared freshly every second day.

\section{Determination of protein concentrations}

Protein concentrations were determined spectrophotometrically by measuring the optical absorbance with a Zeiss PM Q II photometer (Carl Zeiss AG, Zürich, Switzerland). The extinction coefficients used were $E_{280}^{1 \%}=15.7$ for If and $E_{280}^{1 \%}=12.7$ for apo-lf (Brown \& Parry, 1974). A mol. wt of 93000 was chosen for the calculation of molar concentration (Weiner \& Szuchet, 1975).

\section{Antibody production}

Antibodies to If were obtained in 2 series of 5 rabbits by injecting into both foot pads $1.0 \mathrm{mg}$ protein $(1 \mathrm{ml})$, emulsified with an equal volume of Freund's complete adjuvant (Difco). An intravenous injection of $1.5 \mathrm{ml}$ antigen was given $11 \mathrm{~d}$ later. The rabbits were bled $4 \mathrm{~d}$ after the second injection and the antisera pooled. An identical scheme of immunization was repeated when the titres of antisera were not high enough. Immunological assays performed with antisera produced by rabbits immunized with apo-lf were identical to those obtained with antibody to If, probably because the injected apo-lf bound $\mathrm{Fe}$ in the animal.

\section{Immunological assays}

Immunological measurements of heat-induced conformational changes of If and apo-If were performed by the method of micro-complement fixation as described by Levine (1967). In early experiments, an inhibition of complement was observed when the concentration of lf was higher than $0.15 \mu \mathrm{g} / \mathrm{ml}$. It was supposed that the inhibition was provoked by the formation of macromolecular complexes between lf and bovine serum albumin used at a concentration of $0.1 \%(\mathrm{w} / \mathrm{v})$ in buffer for protection of dilute solutions of proteins. Therefore, bovine serum albumin was replaced by $0.1 \%(\mathrm{w} / \mathrm{v})$ gelatin, which solved the problem. In the present study, the equivalence point of the reaction between lf and its specific antibody (corresponding to the peak of the curve of complement fixation), was obtained at a concentration of about $0.08 \mu \mathrm{g} / \mathrm{ml}$, using a pool of 5 antisera diluted 6000 times (more details about the method were given in a previous paper (Baer, Oroz \& Blanc, 1976b).

Quantitative precipitation to investigate the influence on the Fe-binding capacity of apo-If was performed as follows. Antibodies against if were prepared from a pool of 10 antisera by precipitation with ammonium sulphate as described by Stelos (1967), in order to avoid any contamination with Fe from rabbit serum. To the first of 2 serial dilutions containing $0.045-3.0 \mathrm{mg} / \mathrm{ml}$ of apo-lf increasing amounts of ${ }^{59} \mathrm{Fe}-\mathrm{NTA}$ were added. The volume was corrected with buffer in the second serial 
dilution. A constant amount of immunoglobulin $(0.3 \mathrm{ml})$ was then added to each tube of both series and the mixtures were incubated for $1 \mathrm{~h}$ at $37^{\circ} \mathrm{C}$, then overnight at $4{ }^{\circ} \mathrm{C}$. On the following day ${ }^{59} \mathrm{Fe}-\mathrm{NTA}$ was added to the second series. Both series were centrifuged and the antigen-antibody precipitate washed 3 times with cold $0.15 \mathrm{M}-\mathrm{NaCl}$. The radioactivity of the precipitate was measured in a Packard autogamma scintillation spectrometer, type 5210 (Packard Instrument International SA, Zürich, Switzerland).

\section{Spectrophotometric measurements}

The spectra of visible absorption and the titration of $\mathrm{Fe}$, monitored at $460 \mathrm{~nm}$, were performed with a Varian Techtron spectrophotometer, model 635, equipped with a water thermostated cell holder (Varian AG, Zug, Switzerland). A protein concentration of $3.0 \mathrm{mg} / \mathrm{ml}$ was usually used.

\section{Fluorescence measurements}

Fluorescence measurements were performed with a Perkin-Elmer MPF-2A fluorescence spectrophotometer fitted with a water-thermostated cell holder (PerkinElmer AG, Küssnacht, Switzerland). The excitation wavelength was $280 \mathrm{~nm}$. Bandpasses of $10 \mathrm{~nm}$ were selected for the excitation and the emission. The fluorescence spectra were not corrected for the spectral response of the instrument. Protein concentrations used were $400 \mu \mathrm{g} / \mathrm{ml}$ for lf and $150 \mu \mathrm{g} / \mathrm{ml}$ for apo-lf, since the yield of the fluorescence emitted from the Fe-free protein is higher than that of the Fe-lf (Parry \& Brown, 1974).

\section{Heat treatments}

Heating and cooling the solutions of protein were performed in water-thermostated cells directly in the photometer or the fluorimeter. The water circulating in the cell holder was heated with a water-bath Lauda K 2-D (Instrumenten Gesellschaft AG, Zürich, Switzerland). The temperature was continuously checked in the reference cell with a microprobe coupled to a thermometer Mettler, type TM-15 (Mettler Instrumente AG, Greifensee-Zürich, Switzerland). The temperature was always increased at a rate of $1^{\circ} \mathrm{C} / \mathrm{min}$ with equilibration times of $5 \mathrm{~min}$ every $5{ }^{\circ} \mathrm{C}$. The solutions were cooled at a rate of $10^{\circ} \mathrm{C} / \mathrm{min}$. For immunological experiments, $1-\mu \mathrm{l}$ samples were taken at various temperatures and cooled rapidly by dilution with the cold isotonic tris buffer used for complement fixation. To ascertain whether a significant evaporation of solvent occurred at high temperature, the cells were weighed before and after the experiment. The weighings indicated that losses were minute and could further be minimized by putting a loose cap on the cell.

\section{RESULTS}

\section{Heat-induced conformational changes in lactoferrin}

Lf heated at a succession of temperatures, and assayed immediately for antigenic activity with its antibody, gave a series of complement fixation curves superimposable for temperatures up to $55^{\circ} \mathrm{C}$. There was then a progressive diminution of maximal complement fixation at the same antigen concentration until $80^{\circ} \mathrm{C}$. Above that temperature a progressive shift toward the region of higher antigen concentration was observed, accompanied by a decrease in peak height. At $90^{\circ} \mathrm{C}$ the lf no 
(a)

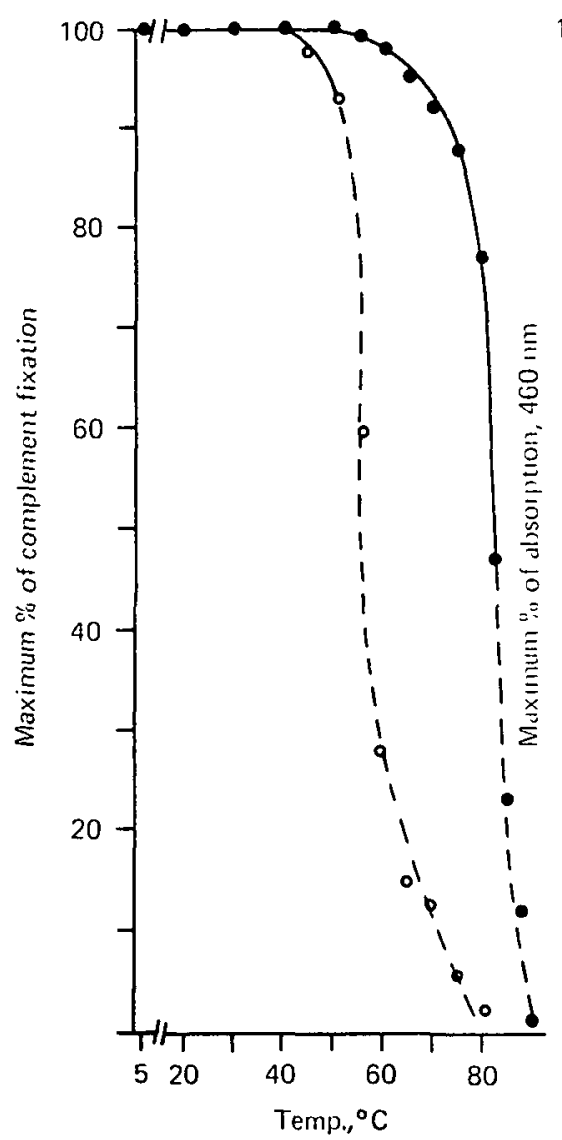

(b)



Fig. 1. Heat stability of lactoferrin (If) and apo-lactoferrin (apo-lf). The proteins, $3 \mathrm{mg} / \mathrm{ml}$, were dissolved in $0.1 \mathrm{M}$-HEPES buffer, $\mathrm{pH} \mathrm{7.0}$ and heated directly in the cells of the photometer. The temperature was increased at a rate of $1^{\circ} \mathrm{C} / \mathrm{min}$ with equilibration times of $5 \min$ every $5^{\circ} \mathrm{C}$. For immunological analyses, $1 \mu \mathrm{l}$ samples were taken at the indicated temperatures, then diluted with buffer at $0^{\circ} \mathrm{C}$ and the complement fixation assay was performed. (a) Decrease of the complement-fixing activity for $(\bullet)$ If and $(O)$ apo-lf as a function of temperature. The percentage of maximum fixation was extrapolated from the percentage of complement fixed by the native protein. The area corresponding to the lateral displacement of the curves of fixation is represented by the dotted line. (b) Decrease of the visible absorption of If, measured at $460 \mathrm{~nm}$, as a function of temperature.

longer displayed any reactivity with its antiserum. The diminution of maximal complement fixation as a function of temperature is shown in Fig. 1(a). The area corresponding to the lateral displacement of the curves is represented by the dotted line. The variations in the intensity of the visible absorption of the protein measured at $460 \mathrm{~nm}$, as a function of the temperature, presented a profile very similar to that obtained from the immunological data (compare Figs $1 a$ and $b$ ). The decrease of the absorbance was produced by the loss of $\mathrm{Fe}$ from the molecule. It was not due to a shift of the visible absorption spectrum, since the maxima of the spectra of the native and the heated protein were observed at $460 \mathrm{~nm}$.

The variation in the intensity of the fluorescence in the course of heating If was very similar to that observed with a solution of tryptophan alone. However, the fluorescence spectrum of the protein showed a progressive shift to longer wavelengths when the temperature was increased above $60^{\circ} \mathrm{C}$. The maximal displacement was 
Table 1. Position of spectral maximum, in $n m$, of the fluorescence of heat-treated lactoferrin and apo-lactoferrin

\begin{tabular}{lcccccc}
\multicolumn{1}{c}{ Protein } & Native & $\begin{array}{c}\text { Heated* } \\
\left(70^{\circ} \mathrm{C}\right)\end{array}$ & Cooled $\dagger$ & $\begin{array}{c}\text { Heated* } \\
\left(85^{\circ} \mathrm{C}\right)\end{array}$ & Cooled & $\begin{array}{c}\text { Addition of } \\
\text { Fe.NTA }\end{array}$ \\
Lactoferrin & $\mathbf{3 3 6}$ & $\mathbf{3 3 8}$ & $\mathbf{3 3 8}$ & $\mathbf{3 4 2}$ & $\mathbf{3 4 2}$ & $\mathbf{3 4 2}$ \\
Apo-lactoforrin & 330 & $\mathbf{3 4 2}$ & $\mathbf{3 3 4}$ & $\mathbf{3 4 2 \S}$ & $\mathbf{3 3 8}$ & $\mathbf{3 4 2}$
\end{tabular}

* The temperature was increased at a rate of $1^{\circ} \mathrm{C} / \mathrm{min}$ with equilibration times of 5 min every $5^{\circ} \mathrm{C}$. $\dagger$ The solution was cooled at a rate of $10^{\circ} \mathrm{C} / \mathrm{min}$ and allowed to stand at $5^{\circ} \mathrm{C}$ for $72 \mathrm{~h}$ before taking the measurements.

$\ddagger$ Iron was added after $72 \mathrm{~h}$ incubation at $5^{\circ} \mathrm{C}$. Molar ratio iron:protein, $3: 1$.

$\S$ Apo-lactoferrin was heated to $80^{\circ} \mathrm{C}$.

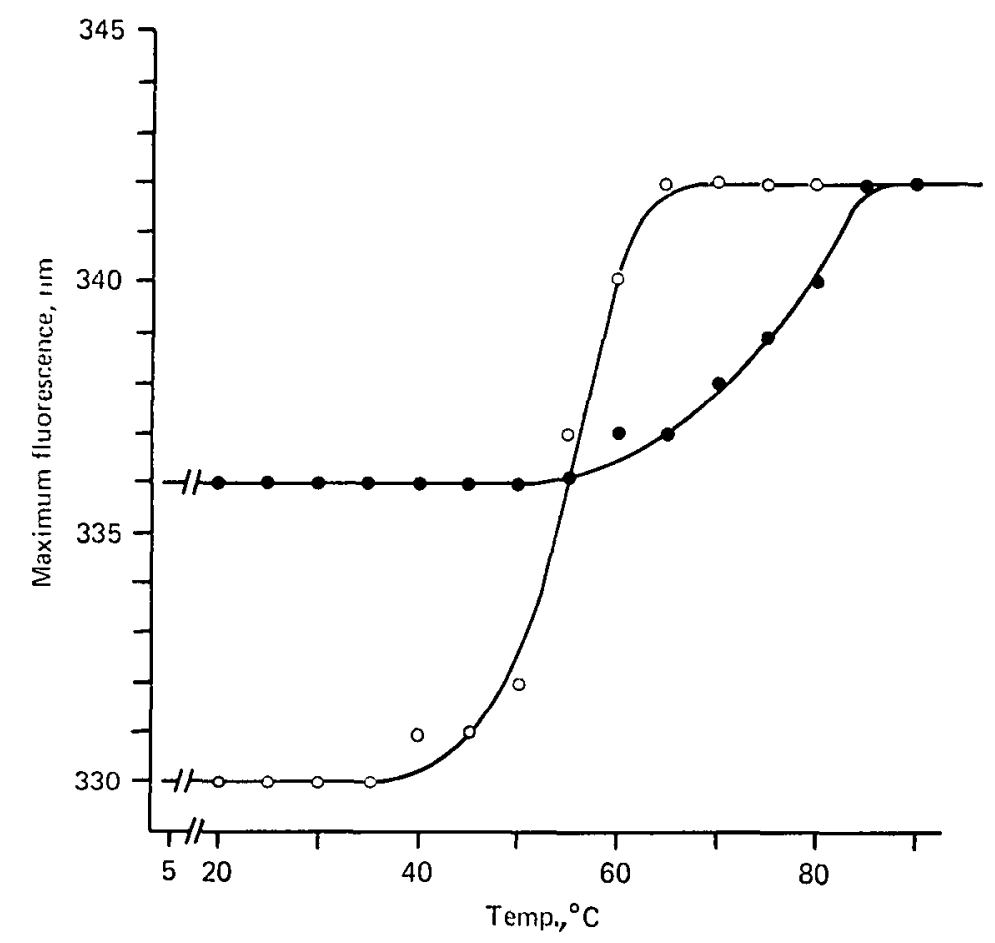

Fig. 2. Wavelengths of maximum fluorescence of lactoferrin (lf, 0 ) and apo-lactoferrin (apo-lf, O), as a function of temperature. The protein, $400 \mu \mathrm{g} / \mathrm{ml}$ for lf and $150 \mu \mathrm{g} / \mathrm{ml}$ for apo-lf, were dissolved and heat-treated as described under Fig. 1.

observed at temperatures above $85^{\circ} \mathrm{C}$ (see Table 1 and Fig. 2). This red shift is most probably due to an unfolding of the molecule, which affects the environment of buried tryptophan residues as they became exposed, since the spectrum is displaced toward the fluorescence maximum of free tryptophan $(350 \mathrm{~nm}$ in our experimental conditions). To investigate a possible reversibility of the denaturation process, If was progressively heated to the desired temperature, at the same rate as for other experiments, and then cooled to $5{ }^{\circ} \mathrm{C}$. The protein was allowed to stand at $5{ }^{\circ} \mathrm{C}$ for times ranging from $5 \mathrm{~min}$ to $72 \mathrm{~h}$ before performing the immunological assay or the fluorescence measurements. The curve of complement fixation obtained with if heated to $85^{\circ} \mathrm{C}$ and immediately assayed for antigenic activity was identical to those obtained with the protein heated and then kept $5 \mathrm{~min}, 1,12$, or $72 \mathrm{~h}$ at $5^{\circ} \mathrm{C}$. There is thus no renaturation influencing the serological properties of the molecule. 


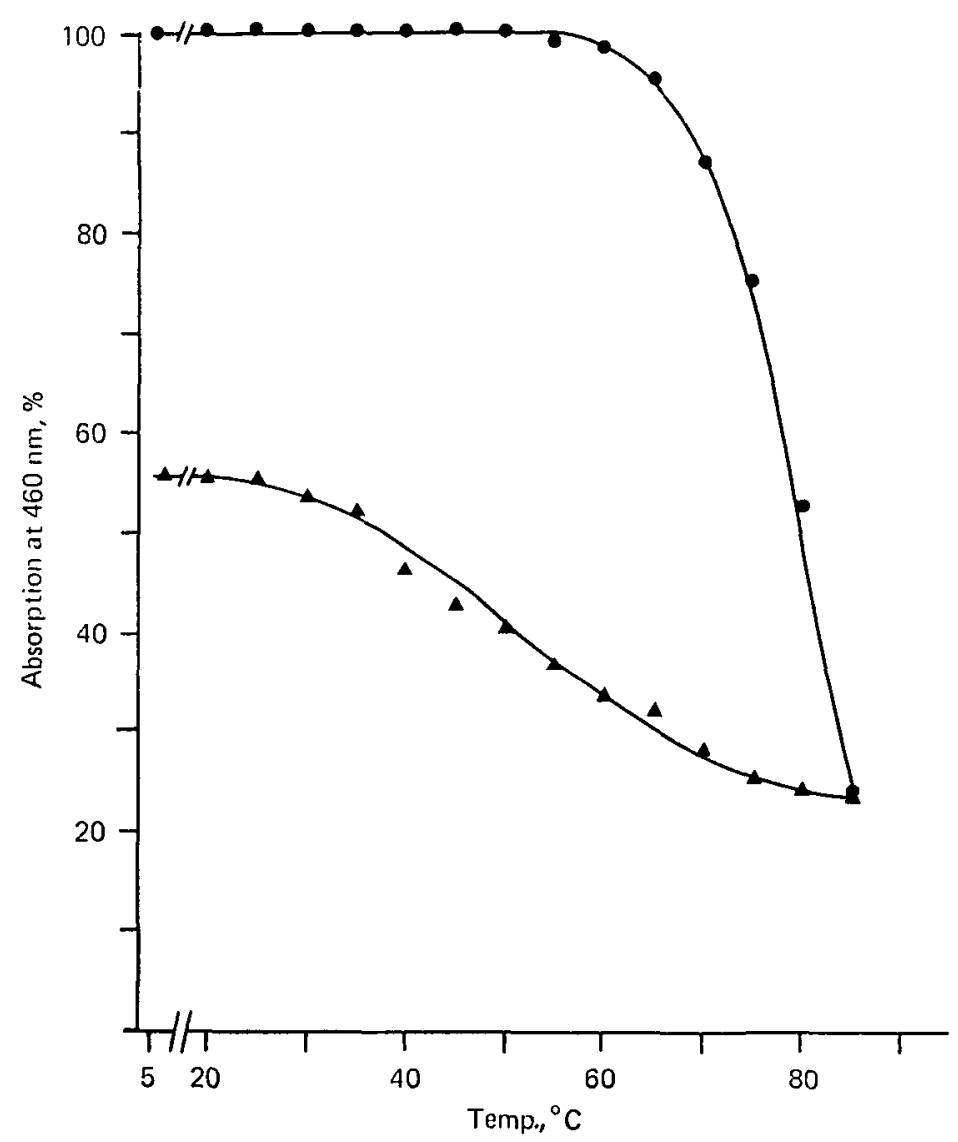

Fig. 3. Variation in the intensity of the visible absorption of lactoferrin, monitored at $460 \mathrm{~nm}$, as a function of $(\Theta)$ increasing and $(\Delta)$ decreasing temperatures. The protein was heated as described under Fig. 1. The temperature was decreased at a rate of $10^{\circ} \mathrm{C} / \mathrm{min}$.

The variation in the intensity of the visible absorption of the protein, measured at $460 \mathrm{~nm}$, during the cooling process showed an interesting phenomenon. The visible absorption of the heated protein measured at $85{ }^{\circ} \mathrm{C}$ was about $25 \%$ of the absorption of the native protein. As the temperature decreased to $5{ }^{\circ} \mathrm{C}$ the intensity of the absorption increased progressively to reach about $55 \%$ of the initial value of the native If (Fig. 3). This percentage did not change when the protein was kept for $72 \mathrm{~h}$ at $5{ }^{\circ} \mathrm{C}$. These results suggest that part of the Fe-binding sites has been renatured without influencing the serological properties of the rest of the molecule. The wavelength of maximum fluorescence of the heated protein was the same when measured immediately at $85^{\circ} \mathrm{C}$ or when measured after standing for $72 \mathrm{~h}$ at $5^{\circ} \mathrm{C}$ (Table 1). These results again are consistent with a lack of renaturation.

\section{Heat-induced conformational changes in apo-lactoferrin}

Apo-lf heated at a succession of temperatures and assayed for its antigenic activity gave a series of complement fixation curves superimposable for temperatures up to $40^{\circ} \mathrm{C}$. There was then a small diminution of maximal complement fixation until $50^{\circ} \mathrm{C}$. Above that temperature, a progressive shift toward the region of higher antigen concentration was observed, accompanied by a drastic decrease in peak 


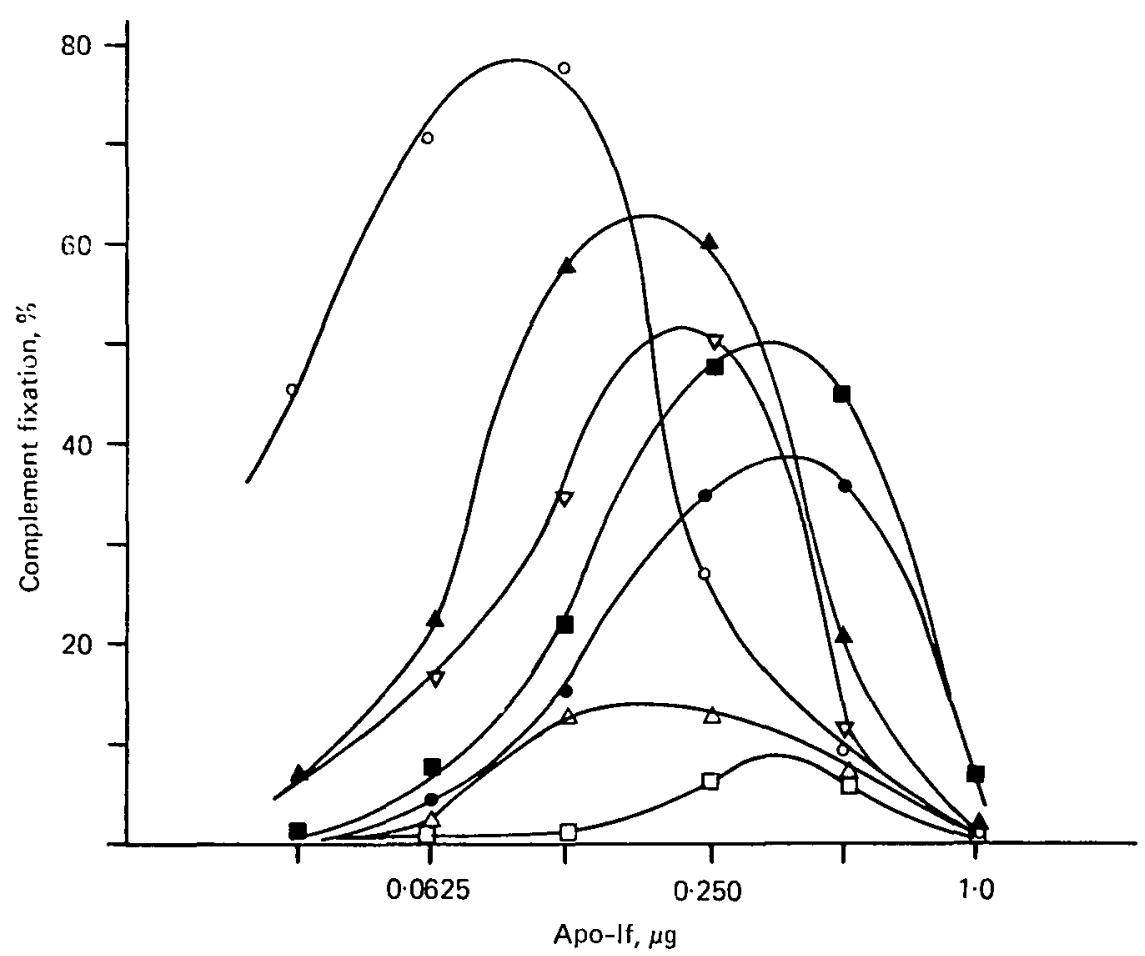

Fig. 4. Serological behaviour of heat-treated apo-lactoferrin (apo-If). The temperature was increased as described under Fig. 1. $O$, Apo-lf native; $\triangle$, apo-If heated to $70^{\circ} \mathrm{C}$ and immediately assayed for complement fixation; $\Delta$, apo-lf heated to $70^{\circ} \mathrm{C}$ and allowed to stand for $72 \mathrm{~h}$ at $5^{\circ} \mathrm{C} ; \nabla$, iron added to the cooled apo-If, in a molar ratio iron:protein, 3:1. $\square$, Apo-lf heated to $80^{\circ} \mathrm{C}$ and immediately assayed; $\boldsymbol{\nabla}$, apo-lf heated to $80^{\circ} \mathrm{C}$ and allowed to stand for $72 \mathrm{~h}$ at $5^{\circ} \mathrm{C} ; 0, \mathrm{Fe}$ added to the cooled apo-lf in a molar ratio Fe:protein, $3: 1$.

height. At $80^{\circ} \mathrm{C}$, the protein no longer displayed any reactivity with its antiserum. This behaviour is shown in Fig. $1(a)$.

The fluorescence spectrum of apo-lf showed a rapid red shift when the temperature was increased above $40^{\circ} \mathrm{C}$. The maximal shift was attained at temperatures above $60{ }^{\circ} \mathrm{C}$ (see Table 1 and Fig. 2). These results indicate a progressive structural disorganization of the molecule which affects the environment of tryptophan residues, as described above for lf.

A possible reversibility of the denaturation process was investigated by comparing the results obtained with the protein assayed immediately after heating, or after a resting time of $72 \mathrm{~h}$ at $5{ }^{\circ} \mathrm{C}$ (heating and cooling conditions were the same as those described for If). The results (Fig. 4), showed that about twice as much antigen was required for maximum complement fixation with the protein heated to $70^{\circ} \mathrm{C}$ as compared with the antigen concentration needed for maximum fixation with the native apo-lf. When the protein was heated to $80^{\circ} \mathrm{C}, 4$ times more antigen was necessary for maximum fixation. In both cases, the incubation time at $5^{\circ} \mathrm{C}$ did not modify the concentration of antigen needed for maximum fixation, but the peak height increased by about 5 times. These results suggest that heat treatment of apo-If at 70 or $80{ }^{\circ} \mathrm{C}$ rendered about 50 or $75 \%$ respectively of the molecules serologically inactive. The antigenicity of the remaining protein was also diminished, since the peak height of the curves was not as high as that obtained with native 


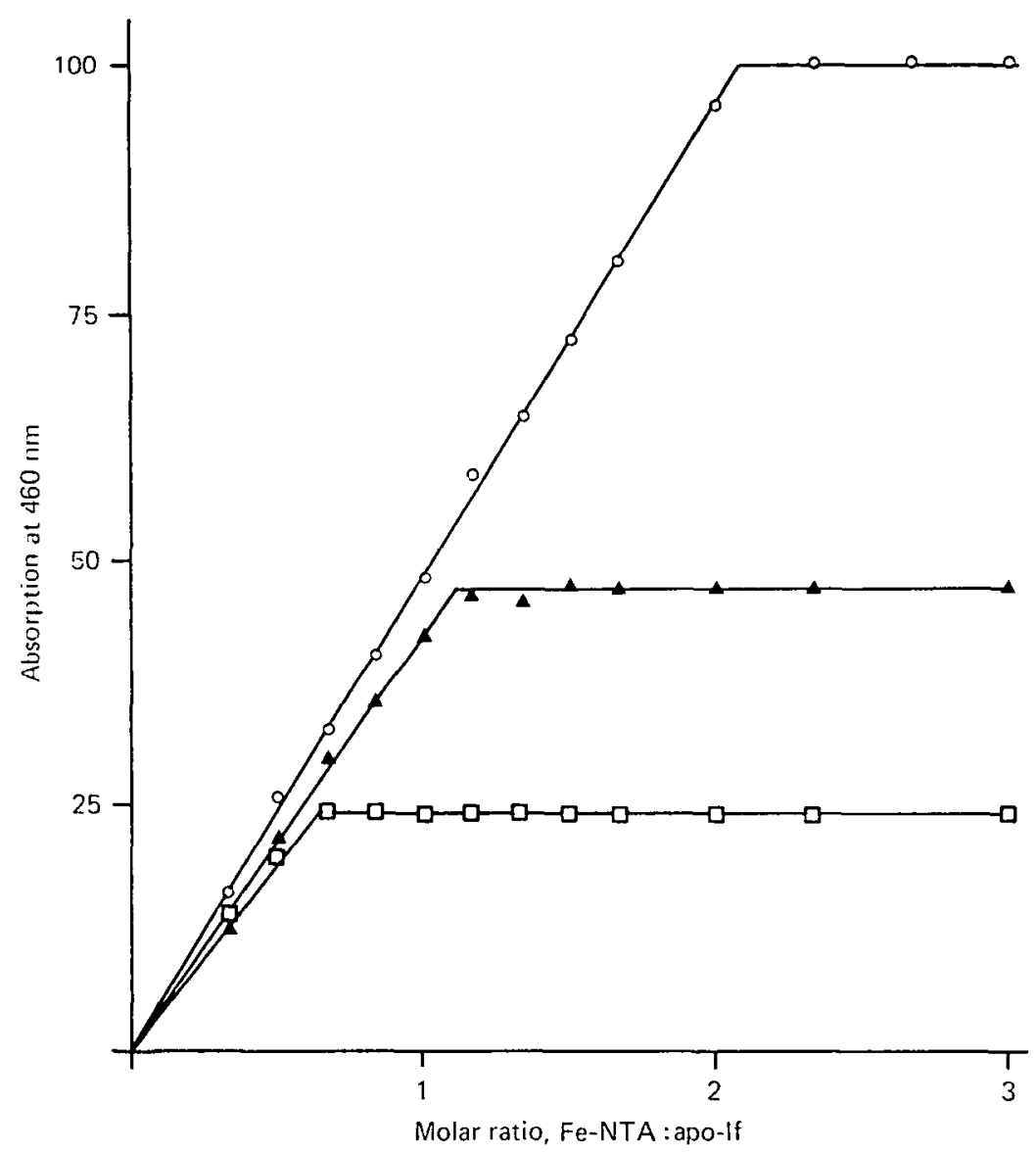

Fig. 5. Residual Fe-binding capacity of heat-treated apo-lactoferrin (apo-lf). The protein was heated as described under Fig. 1 , cooled at a rate of $10^{\circ} \mathrm{C} / \mathrm{min}$ and allowed to stand at $5{ }^{\circ} \mathrm{C}$ for $72 \mathrm{~h}$. It was then distributed in a series of samples and $1 \mu \mathrm{l}$ of buffer containing increasing amount of Fe-NTA was added. $\mathrm{O}$, Native apo-lf; $\Delta$, apo-lf heated to $70^{\circ} \mathrm{C} ; \square$, apo-If heated to $80^{\circ} \mathrm{C}$.

apo-lf. However, the loss of the antigenicity of the remaining apo-lf could be partially restored by keeping the protein at $5{ }^{\circ} \mathrm{C}$ for $72 \mathrm{~h}$. These results were not further modified by an incubation at $5{ }^{\circ} \mathrm{C}$ for $96 \mathrm{~h}$. This shows that the renaturation process was already maximal after $72 \mathrm{~h}$ of incubation.

The fluorescence measurements of the protein kept at $5{ }^{\circ} \mathrm{C}$ for $72 \mathrm{~h}$ indicated a diminution of the wavelength of maximum fluorescence from 342 to $336 \mathrm{~nm}$ and from 342 to $338 \mathrm{~nm}$ for the cooled protein exposed to temperatures of 70 or $80^{\circ} \mathrm{C}$ respectively (Table 1). These results may reflect an incomplete or an incorrect refolding of the molecule indicated by its partly restored antigenicity.

To determine whether the denaturation process of apo-lf did affect the Fe-binding sites of the molecule, the following experiment was done: 2 batches of apo-lf heated to 70 and $80^{\circ} \mathrm{C}$ were kept at $5{ }^{\circ} \mathrm{C}$ for $72 \mathrm{~h}$, then distributed in series of 12 samples of $0.5 \mathrm{ml}$. To each sample of a series, $1.0 \mu \mathrm{l}$ of buffer containing increasing amounts of Fe-NTA was added. The molar ratio of Fe to apo-lf of the last sample was $3: 1$. The mixtures were kept at $5{ }^{\circ} \mathrm{C}$ overnight and then the visible absorption measured at $460 \mathrm{~nm}$. The results (Fig. 5) showed that apo-lf heated at $70^{\circ} \mathrm{C}$ was still able to bind 
about $50 \%$ of the amount of Fe bound by the native protein. However, the rate of increasing absorbance as a function of the amount of Fe added was not as high as that observed with the unheated protein. The results obtained with apo-lf heated to $80^{\circ} \mathrm{C}$ indicated that the protein was still able to complex about $25 \%$ of the amount of Fe bound by the unheated molecule. There was also a diminution of the rate of increasing absorbance, as described for apo-lf heated to $70^{\circ} \mathrm{C}$.

The addition of $\mathrm{Fe}$ to apo-lf exposed to 70 or $80^{\circ} \mathrm{C}$ changed the conformation of the molecule, as reflected by the complement fixation assay (Fig. 4). The amount of complement fixed was lower by about $12 \%$ after addition of $\mathrm{Fe}$, as compared to the curves obtained without Fe. A discrete shift of the curves toward the region of more antigen was also observed.

These results were confirmed by the fluorescence measurements, also indicating a structural modification of the molecule induced by the addition of Fe since the wavelength of maximum fluorescence increased from the values of the 'renatured' form (336 or $338 \mathrm{~nm}$ ) to the value of the 'denatured' form $(342 \mathrm{~nm}$ ), as indicated in Table 1.

In order to investigate whether the antisera contained any antibodies to the Febinding moiety of the molecule, 2 quantitative precipitin curves were realized (see Materials and Methods). The first one was obtained with apo-lf saturated with ${ }^{59} \mathrm{Fe}-\mathrm{NTA}$ before adding the antibody. The second one was obtained with apo-lf first complexed with its antibody and then mixed with ${ }^{59} \mathrm{Fe}-\mathrm{NTA}$. The curves drawn by plotting the radioactivity contained in the precipitate as a function of the antigen concentration were practically superimposable, demonstrating that the complex formation between apo-lf and its antibody did not cause any loss of Fe-binding capacity of the molecule. The results suggest that the antisera contained no antibodies to the Fe-binding sites of the protein, if one assumes that antibody against the site itself would prevent $\mathrm{Fe}$ fixation or, at least, diminish the affinity of the site for $\mathrm{Fe}$ by steric hindrance.

\section{Fe-lactoferrin}

DISCUSSION

The similarity between both profiles of the curves of Fig. 1 ( $a$ and $b$ ) (plot of maximum per cent of complement fixation or maximum per cent of optical density at $460 \mathrm{~nm}$, versus temperature) may be explained as follows. The loss of $\mathrm{Fe}$ is produced by a structural change of the Fe-binding sites detected by the immunological analyses. The decrease in maximal complement fixation observed at the same antigen concentration for temperatures up to $80^{\circ} \mathrm{C}$ may reflect destruction on the molecule of antigenic sites, which could correspond to the polypeptide framework involved in the conformation of the Fe-binding sites. The progressive lateral displacement of the complement fixation peak observed above temperatures of $80^{\circ} \mathrm{C}$ indicates probably an irreversible loss of the antigenicity of an increasing fraction of the molecules. The irreversibility of the denaturation process was reflected by the immunological and the fluorescence experiments performed with lf allowed to stand at $5^{\circ} \mathrm{C}$ for $72 \mathrm{~h}$. However, the $\mathrm{Fe}$-binding ability of the protein was partially restored when it was cooled. It was also demonstrated serologically that the antisera did not contain any antibody to the Fe-binding sites themselves; thus the parallelism between the 2 curves in Figs 1 ( $a$ and $b$ ) suggest that part(s) of the molecule surrounding the binding sites is (are) modified, possibly affecting the affinity of $\mathrm{Fe}$ for the binding sites. 
The influence of Fe-binding on the fluorescence behaviour of the native protein was as follows. The complex formation of apo-If with Fe led to a shift of the emission maximum, indicating a structural modification, which involved some tryptophan residues. The shift was toward longer wavelengths, indicating a transfer of the tryptophan residues from a rather hydrophobic to a more polar environment (Lehrer \& Fasman, 1967). The red shift was accompanied by a decrease in the peak height of the fluorescence, most probably brought about by Fe itself. Heating if produced a progressive red shift, beginning at the same temperature as did the immunologic and photometric modifications. There was also an increase in fluorescence intensity due to the diminution of such quenching as the lf lose Fe on heating. As the shift was toward longer wavelengths, the loss of Fe did not induce a return to a structure similar to the original apo-lf, but produced an unfolding of the protein which exposed the buried tryptophan residues. The wavelength of $342 \mathrm{~nm}$ corresponds to the maximum of the heat-induced unfolding of the molecule, since heating above $85^{\circ} \mathrm{C}$ did not modify the emission maximum, nor the yield of the fluorescence. The Febinding capacity could be partly restored in the cold protein without influencing the polarity of the environment of the tryptophan residues. Therefore, one can deduce that these residues are not directly involved in the Fe-binding sites but belong to the surrounding polypeptide framework of the molecule.

\section{Apo-lactoferrin}

The immunological analyses indicated a structural modification of apo-lf beginning at $45^{\circ} \mathrm{C}$, demonstrating that the heat stability of the Fe-free protein was lower than the Fe-saturated form (see Fig. 1a). The lateral displacement of the curves of complement fixation indicated a complete loss of the antigenicity of an increasing fraction of the molecules (this fraction corresponded to $50 \%$ of the protein heated at $70^{\circ} \mathrm{C}$ and to $75 \%$ of the protein heated at $80^{\circ} \mathrm{C}$ ). The decrease in maximum complement fixation observed with the remaining serologically active molecules demonstrated a diminution of the affinity of the antigen for its antibody. The increase in peak height of the curve observed with the protein allowed to stand at $5{ }^{\circ} \mathrm{C}$ for $72 \mathrm{~h}$ reflected a partial restoration of the antigenic competence with the antibody. However, this competence was diminished by the addition of Fe. Assuming that the partial renaturation tends to give apo-lf a conformation similar to that of the native protein, addition of $\mathrm{Fe}$ should produce a molecular structure disclosing a higher antigenic activity. Since such a phenomenon was experimentally not observed, one can consider the 'renatured' form of apo-lf as an incorrect refolding, whose structure is disturbed by the fixation of Fe.

These results were confirmed by the fluorescence analyses. The emission maximum observed at $342 \mathrm{~nm}$ corresponds to the maximal unfolding of the heated molecule. Keeping the solution at $5{ }^{\circ} \mathrm{C}$ for $72 \mathrm{~h}$ produced a blue shift to 334 or $338 \mathrm{~nm}$ depending on the heat treatment (see Table 1). Thus, the refolding of certain portions of the molecule produced an alignment of the tryptophan residues in a conformation similar to the original. The addition of $\mathrm{Fe}$ should influence the environment of the tryptophan residues contained in the Fe-binding moiety of the heated molecule in the same way as when $\mathrm{Fe}$ is added to the native apo-lf. However, Fe-binding provoked a red shift corresponding to the emission maximum of the unfolded protein, suggesting that the 'renaturation' of heated apo-lf corresponds to an incorrect partial refolding. Fe-binding produced an increased exposure of tryptophan residues without any 
quenching, suggesting strongly that these amino acids are not directly implicated in the binding sites themselves. The exposure of buried tryptophan residues did not provoke the disorganization of the same antigenic determinants, since the immunological behaviour of If and apo-lf are not the same.

The binding of $\mathrm{Fe}$ to the molecule results in a conformation in which tryptophan residues are less subject to environmental changes when the temperature is increased, as indicated by the higher temperature needed to induce unfolding of lf. The resistance to heat-induced denaturation of the 2 binding sites is high and apparently independent of the degree of denaturation of the rest of the molecule, since a completely unfolded apo-lf is still able to bind Fe specifically. This is also true for lf which can complex Fe even when serologically almost unreactive.

The lack of an evident interdependence between the conformation of the molecule and its Fe-binding capacity may suggest that the binding moieties did not change very much in the course of evolution. The binding sites of If may thus be similar to the binding sites of other Fe-binding proteins such as transferrins and conalbumins. The rest of the molecule on the contrary, may have been more subject to mutation, since its conformation does not influence markedly the function of the protein.

We are grateful to Dr M. Casey for his interest in this work and for his linguistic assistance.

\section{REFERENCES}

BAEr, A., Oroz, M. \& Blanc, B. (1976a). Milchwissenschaft 31, 649.

BAER, A., ORoz, M. \& Blanc, B. (1976b). Journal of Dairy Research 43, 419.

Bates, G. W. \& Wernicke, J. (1971). Journal of Biological Chemistry 246, 3679.

Bishop, J. G., Schanbacher, F. L., Ferguson, L. C. \& Smit, K. L. (1976). Infection and Immunity 14, 911.

Brınc, B. \& Isliker, H. S. (1961). Helvetica Physiologica Acta 19, C 13.

Brown, E. M. \& PaRRY, R. M. Jr (1974). Biochemistry 13, 4560.

Groves, M. L. (1960). Journal of the American Chemical Society 82, 3345.

LAw, B. A. \& ReiTer, B. (1977). Journal of Dairy Research 44, 595.

Lehrer, S. S. \& Fasman, G. D. (1967). Journal of Biological Chemistry 242, 4644.

LEviNe, L. (1967). In Handbook of Experimental Immunology,p. 707. (Ed. D. M. Weir.) Oxford: Blackwell Sciontific Publications.

Masson, P. L., Heremans, J. F. \& Dive, C. (1966). Clinica Chimica Acta 14, 735.

Montreut, J. \& MuLuet, S. (1960). Comptes Rendus de l'Académie des Sciences 250, 1736.

Parry, R. M. Jr \& Brown, E. M. (1974). In Advances in Experimental Medicine and Biology: ProteinMetal Interactions, p. 141. (Ed. M. Friedman.) New York, N.Y.: Plenum Press.

RÜHGG, M., Moon, U. \& Bland, B. (1977). Journal of Dairy Research 44, 509.

Stelos, P. (1967). In Handbook of Experimental Immunology, p. 3. (Ed. D. M. Weir.) Oxford: Blackwell Sciontific Publications.

WeINER, R. E. \& SzUCHET, S. (1975). Biochimica et Biophysica Acta 393, 143. 